\title{
MRI based biomechanical parameters for carotid artery plaque vulnerability assessment
}

L. Speelman ${ }^{1 *}$, PhD, Z. Teng ${ }^{2}$, PhD, A.J. Nederveen ${ }^{3}$, PhD, A. Van der Lugt ${ }^{4}$, MD, PhD, J.H. Gillard ${ }^{2}$, MD 1 Department of Biomedical Engineering, Erasmus Medical Center, Rotterdam 3000 CA, The Netherlands

2 Department of Radiology, University of Cambridge, School of Clinical Medicine, Box 218 Cambridge Biomedical Campus, Cambridge CB2 0QQ, UK

3 Department of Radiology, Academic Medical Center Amsterdam, University of Amsterdam, Meibergdreef 9, 1105 AZ Amsterdam, The Netherlands

4 Department of Radiology, Erasmus Medical Center, Rotterdam 3000 CA, The Netherlands

* Corresponding author

Dr. Lambert Speelman

\section{L.speelman@erasmusmc.nl}

Department of Biomedical Engineering, Ee 23.38B

P.O Box 2040, 3000 CA Rotterdam, the Netherlands

Tel. 0031107044039

Fax. 0031107044720 


\begin{abstract}
Carotid atherosclerotic plaques are a major cause of ischemic stroke. The biomechanical environment to which the arterial wall and plaque is subjected to plays an important role in the initiation, progression and rupture of carotid plaques. MRI is frequently used to characterize the morphology of a carotid plaque, but new developments in MRI enable more functional assessment of carotid plaques. In this review, MRI based biomechanical parameters are evaluated on their current status, clinical applicability, and future developments. Blood flow related biomechanical parameters, including endothelial wall shear stress and oscillatory shear index, have been shown to be related to plaque formation. Deriving these parameters directly from MRI flow measurements is feasible and has great potential for future carotid plaque development prediction. Blood pressure induced stresses in a plaque may exceed the tissue strength, potentially leading to plaque rupture. Multicontrast MRI based stress calculations in combination with tissue strength assessment based on MRI inflammation imaging may provide a plaque stress-strength balance that can be used to assess the plaque rupture risk potential. Direct plaque strain analysis based on dynamic MRI is already able to identify local plaque displacement during the cardiac cycle. However, clinical evidence linking MRI strain to plaque vulnerability is still lacking. MRI based biomechanical parameters may lead to improved assessment of carotid plaque development and rupture risk. However, better MRI systems and faster sequences are required to improve the spatial and temporal resolution, as well as increase the image contrast and signal-to-noise ratio.
\end{abstract}




\section{Introduction}

Carotid atherosclerotic plaques are a major cause of ischemic stroke. Currently, the degree of carotid luminal stenosis is the only valid criterion that is associated with an increased risk of ischemic stroke and is used in clinical decision making to assess the severity of atherosclerotic disease. However, increasing evidence has shown a close association between the structure and morphology of the carotid plaque and patient clinical presentations (1) , plaque progression (2) and the probability of subsequent ischemic cerebrovascular events $(3,4)$. Magnetic Resonance Imaging (MRI) is capable of characterizing carotid plaque morphology accurately $(5)$ and with good reproducibility $(6,7)$. Multicontrast MRI is generally used to identify the different plaque components. Using the basic contrast weightings $T 1, T 2$, and proton density, obtained with black blood sequences, the key features of a plaque can be identified, like fibrous tissue, lipid core (8), intraplaque hemorrhage (IPH) (9), and calcium (10). With high-resolution MRI, the status of the fibrous cap (FC) can even be assessed (11) and the intermediate and advanced lesions can be distinguished (12). New developments in MRI enable more functional assessment of carotid plaques, including detailed flow conditions $(13,14)$, wall and plaque displacement and strain $(15)$, and plaque inflammatory status (16).

The biomechanical environment, to which the arterial wall and plaque is subjected to, plays an important role in the initiation, development, and atherosclerotic plaque rupture. Blood flow related biomechanical parameters, including wall shear stress (WSS), have been shown to be involved in plaque initiation (17), plaque progression (18), and changes in plaque composition (19). Additionally, blood pressure induced stresses and strains in the plaque can exceed the material strength of the supporting tissues, potentially leading to plaque disruption and thrombosis (20).

In this review, the potential of MRI based biomechanical parameters to improve the accuracy in assessing carotid artery plaque vulnerability are discussed. The techniques detailed in this review focus on flow related biomechanical parameters, displacement and strain parameters, and on stress and failure strength of carotid plaque tissue. The current status of these techniques and the future developments will be explored, assessing whether they may translate into clinical practice.

\section{Flow related biomechanical parameters}

Plaque development has been shown to be related to low or low and oscillatory WSS, a force exerted on the endothelial cells by the flowing blood $(17,21)$. WSS is also believed to play a role in plaque progression (18) and changes in plaque composition (19). Information on WSS and related biomechanical parameters can improve our understanding of carotid atherosclerosis $(22,23)$. WSS in a carotid artery bifurcation can be calculated using computational fluid dynamics (CFD) (24). Based on the lumen geometry, coupled with flow and pressure boundary conditions, the NavierStokes equations can be solved to obtain a high resolution blood velocity field throughout the complete geometry. WSS is calculated by multiplying the dynamic viscosity of blood with the shear rate, which is the radial spatial gradient of the velocity field at the vessel wall. However, CFD requires long computational times and accurate boundary conditions. Alternatively, WSS can be directly derived from the velocity field measured with phase contrast (PC) MRI $(13,14,25-27)$. This way, the carotid artery shear rate can be obtained faster and without complex CFD calculations. These calculations were generally based on 2D PC MRI studies $(28,29)$. Time averaged 3D flow data or time 
resolved 3D PC MRI (also termed '4D flow MRI') data have recently been used to obtain 3D WSS distribution of carotid artery geometries $(13,27)$.

To determine the local shear rate from an MRI velocity field, the vessel wall boundary needs to be identified, either by manual or automatic delineation of the MRI images (Figure 1) (30). The tangential and perpendicular velocity components close to the wall can be used in a curve fitting method to derive the shear rate at the wall using linear (31) or quadratic (32) fits or more advanced interpolation functions (27,33-36). To avoid incorrect shear rates due to over- or underestimated lumen areas, a minimum of 8 voxels in vessel diameter and a 10:1 signal-to-noise (SNR) ratio of the PC MRI is advised $(27,37)$. Typically, 3D PC MRI carotid artery studies are performed with a spatial resolution in the order of 0.6-1 $\mathrm{mm}^{3}$, but with a limited number of 8 to 10 time steps over the cardiac cycle. Although generally the patterns of MRI based WSS are similar to CFD based WSS (13), the levels of MRI based WSS are influenced by the spatial resolution of PC MRI $(13,26,27,38,39)$. Especially for higher shear stress values, the accuracy of MRI based WSS tends to be significantly underestimated compared to CFD WSS $(13,39)$. This underestimation increases with lower spatial resolution $(13,26)$. Therefore, relative shear stress parameters are generally presented and may be more appropriate to evaluate as clinical markers, for instance by comparing patient specific shear stress maps with ensemble-average shear stress maps of a control populations (40).

When measuring blood flow velocities with PC MRI, a velocity encoding (VENC) value needs to be set, which determines the maximum range at which velocities can be measured. With a relative high VENC setting (higher than the maximum blood flow velocity), low velocity signals will be measured. With a relative low VENC setting, blood velocities exceeding the VENC will undergo phase wrapping and show up as an incorrect velocity. Such artifacts cannot be easily resolved with post processing and complicates the quantitative interpretation of the velocity maps. The VENC should therefore be appropriately chosen to comply with the maximum velocity in the area of interest. Other sources of inaccuracies in MRI velocity data include phase offset errors (41) and intravoxel dephasing (42). Although corrective methods are available for these errors, they may be dominant in specific geometries, e.g. highly stenotic or tortuous carotid arteries, making them unsuitable for current PC MRI sequences.

Besides WSS, studies have shown that changes in WSS direction over the cardiac cycle may promote atherosclerosis (43-45). These directional changes can be quantified by the oscillatory shear index (OSI) (46). OSI ranges between 0 and 0.5 , where higher values indicate more variation in WSS direction. As OSI is a measure of temporal changes of the WSS, an accurate evaluation of MRI based OSI is only possible with time-dependent velocity information with high spatial and temporal resolutions. Although MRI based OSI is intrinsically challenging due to the trade-off between spatial resolution and temporal resolution, several studies demonstrated the feasibility of MRI based OSI in carotid arteries $(29,39,47)$. Clinical evaluations are required to investigate the diagnostic value of MRI derived WSS and OSI.

Using CFD calculations, a variety of hemodynamic wall parameters have been evaluated and compared (23). The relative residence time (RRT) was shown to be a robust metric and might therefore be appropriate as a single metric to replace WSS and OSI to characterize low and oscillatory wall shear stress (23). More recently, new hemodynamic parameters have been suggested, such as localized normalized helicity of the flow (48) and transverse wall shear stress (transWSS), which characterizes the multi-directionality of the flow field (45). TransWSS seems to 
localize better with plaque locations than time averaged WSS, OSI, or RRT, although clinical studies should be performed to evaluate whether it holds for MRI based hemodynamic measurements.

In the future, advanced MRI acceleration techniques can be used to reduce the imaging times and the noise levels, allowing MRI scans to be acquired at higher spatial and temporal resolutions (4951). Deriving carotid shear stress directly from MR flow measurements seems to be feasible when all requirements are taken into account. However, clinical evidence that MRI based shear stress parameters relate to future clinical events still needs to be provided. As MRI based WSS analysis is more straightforward and less time consuming than CFD calculations, MRI based WSS has a great potential in improving the prognostication of future carotid plaque related clinical events.

\section{Stress and strength parameters}

The degree of carotid luminal stenosis as diagnostic criterion becomes less reliable in patients with mild to moderate carotid stenosis (52). Increasing evidence suggests that the physical characteristics of atherosclerotic plaques may have a greater potential to predict progression and clinical events than luminal stenosis alone $(3,20)$.

A vulnerable carotid atherosclerotic plaque is characterized by a thin FC, a large, lipid-rich necrotic core, inflammatory cells, and frequently the presence of IPH. Symptomatic plaques are associated with FC rupture. IPH and FC rupture can be quantified accurately by in vivo high-resolution, multicontrast MRI (53-55), and have shown to predict future clinical events in symptomatic (56) and asymptomatic $(4,57)$ patients. FC rupture is thought to be the precipitating factor in the majority of clinical events, and occurs when the mechanical loading due to flow and pressure exceeds the strength of the tissue. Indeed, high mechanical stress concentrations in plaques were associated with fissuring in both coronary (58) and carotid (20) plaques. Furthermore, stress levels within a FC can differentiate symptomatic from asymptomatic patients (59), and are associated with subsequent cerebrovascular ischemic events in symptomatic patients (60).

The combination of MR-depicted compositional plaque features and mechanical analysis may have the potential for a more accurate plaque vulnerability assessment. Structural stress levels within the plaque cannot be directly measured. Finite element method (FEM)-based analysis has been widely used to estimate stresses in atherosclerotic plaques indirectly $(20,61,62)$. For these stress calculations, the plaque geometry, tissue material properties, and loading conditions are required (63). The loading conditions are generally estimated using brachial artery pressures.

Successful FEM plaque analysis requires intensive manual image processing, geometrical reconstruction of the plaque and considerable computational time. In particular, each model may take a few days to successfully perform a 3D fluid structure interaction (FSI) analysis, which is thought to be the most accurate computational strategy (64). A fast computational protocol is, therefore, needed if this technique is to be fully translated into the clinic. For mild to moderately stenotic carotid plaques, a 3D structure-only model is reasonably accurate and computationally inexpensive, as compared with 3D FSI simulations (64). Although in 2D simulations the qualitative stress distribution in the plaque is mainly unaltered, 3D simulations seem to be a requirement for accurate peak stress calculations (65).

Carotid plaque geometry (lumen, lipid core, outer wall, calcifications, and IPH) can be reconstructed from multi-contrast MRI, using manual or automatic segmentation techniques (Figure 2). The accuracy of the segmentation is frequently limited by the imaging resolution. Most clinically oriented FEM analyses are based on 2D fast spin echo (FSE) MRI with an in-plane resolution around $0.4 \times 0.4$ $\mathrm{mm}^{2}$ and a slice thickness of 2-3 $\mathrm{mm}(20,66)$. Due to these thick slices, partial volume effects may 
occur, leading to a misrepresentation of plaque characteristics. Additionally, Imaging the plaque under an oblique plane orientation can obscure a FC thickness assessment, especially when the slice thickness is much larger than the in-plane image resolution (67). Advanced 3D isotropic MR sequences generally exhibit a lower in-plane resolution (0.6-1 $\mathrm{mm}$ ), but can image a larger volume with thinner slices (68-70). A thin FC, a key feature of a high-risk plaque (71), may be hardly visible. Thus, geometrical assessment of carotid plaques based on MRI is currently only reliable for plaques with thicker caps. Calcification, IPH and lipid-rich necrotic cores can be identified with high resolution, multi-contrast MRI with a moderate-to-good sensitivity and specificity (5). Given de limited dimensions of the vessel wall and plaques components, high resolution imaging is desirable. However, pushing the spatial resolution to the extreme is impossible because of scan time limitations and the available SNR. Over de past decade the use of a dedicated phased array neck surface coil with either 4 or 8 channels has become more and more standard for carotid imaging [Balu et al. J Magn Res Imag 2009]. The use of either a conventional head and neck coil or a single element surface coil does not deliver sufficient image quality.

Recent advances in quantitative MR sequences, such as $T_{1}$ and $T_{2}$ mapping (72) have the potential to further improve the discriminatory power between different tissue types. Further improvements in resolution, SNR, and clinically feasible imaging times (about 10-15 minutes) may be achieved with higher magnetic field strength, such as 7 Tesla MRI (73). Additionally, novel MRI sequences $(74,75)$ and acceleration techniques (76) are needed to reduce imaging time and to improve image resolution and SNR.

A further important aspect to plaque stress calculations regards the material properties of the atherosclerotic plaque tissues. Experimental measurements of the material properties are limited (77-80), in particular those that consider nonlinear material behavior. Furthermore, the experimental measurements generally show a large variation in material properties within and between patients. This variation may have a great impact in stress calculations, in particular when the FC is thin $(81,82)$. Displacement or strain data of carotid plaques measured with dynamic MRI acquisitions can also be used to evaluate the mechanical properties of the tissue locally (83-85). In the next section, MRI techniques are discussed that may be used to measure deformation on strain in a carotid plaque in vivo. To derive plaque material properties, biomechanical FEM models are created from multi-contrast MRI that reflect the geometry of the plaque. Displacements calculated with FEM can then be matched with the MRI measured displacements by optimizing the material properties of the plaque components in the model (83). Based on the patient-specific estimate of the material plaque properties, FEM can provide stresses and strains in a plaque. As the accuracy with which the material properties can be estimated depends on the accuracy of the plaque geometry and the accuracy of the displacement calculations with MRI, validation is needed to truly assess the reliability of these techniques. So far, only fully elastic material models are used to assess the mechanical behavior of arteries based on MRI. The intrinsic viscous properties of arterial tissue may play a role in the general behavior of the tissue and the stress/strain response due to the cyclic blood pressure. To estimate the viscous effects, also pressure waveforms are required that are timeregistered with the area variation measurements of the vessel. Pressure waveforms in the carotid artery can be measured using applanation tonometry, although MRI based methods have also been proposed, based on Fourier velocity encoded M-mode MRI (86).

When stresses within a plaque are computed, a strength threshold is needed as a reference, above which the lesion may be unstable and induce subsequent ischemic events. The $300 \mathrm{kPa}$ threshold possible is the most widely used (63). However, this threshold is based on mechanical testing of 
human aortic plaque caps (87) and different vascular territories likely contain plaques with different morphological and mechanical features. In order to establish a useful strength threshold for FC, direct material testing is necessary, for instance following the suggested testing protocol from Walsh et al. (2014) (88). The study that provided the $300 \mathrm{kPa}$ threshold also showed that FCs of ruptured plaques exhibit a higher degree of inflammation than caps from unruptured plaques (87). Increased inflammatory status of a plaque can lead to degradation of the extracellular matrix and thereby weakening of the plaque. Information on the inflammatory status may therefore provide vital information on the (relative) strength of a plaque. Molecular imaging may provide in vivo information on the plaque inflammatory status. Currently, vascular inflammation is best measured by co-registration of 18-F-FDG PET and CT imaging [Alie et al. Clin Med Insights Cardiol. 2015]. More recently, $\mathrm{PET} / \mathrm{MRI}$ was proposed for the excellent soft tissue contrast of $\mathrm{MRI}$, but this technique is not frequently used in the clinic yet. Research in the MRI field has focused on specific MRI acquisition sequences and targeted MRI contrast media to evaluate the plaque inflammatory status with MRI alone. These initiatives are currently being developed and validated against PET/CT imaging and it may take a number of years before they can be employed in the clinic $(16,89,90)$.

\section{Displacement and strain parameters}

The composition of an atherosclerotic plaque generally has an effect on the deformation of the plaque over the cardiac cycle; soft plaques will deform more than stiff plaques under the same pressure conditions. Determining plaque deformation may therefore be valuable for an improved assessment of plaque composition. Previous studies in coronary and femoral artery plaques showed that, with invasive ultrasound measurements, strain values can indeed serve as a surrogate marker for plaque composition and vulnerability $(91,92)$.

Different MRI techniques may be used to derive carotid artery deformation in vivo (15). Cine MRI is capable of recording carotid movement over the cardiac cycle. It is a widely used imaging protocol with acceptable spatial $\underline{\left(0.6-1 \mathrm{~mm}^{3}\right)}$ and temporal resolutions $\underline{(20-50 \mathrm{~ms})}$ and the starting point of many post-processing techniques to derive plaque deformation $(83,93)$. A drawback of conventional cine MRI is that only the lumen boundary is visible, whereas the vessel wall is hardly visible due to the limited spatial resolution and SNR of the wall compared to the lumen. By applying blood suppression (Black Blood imaging), the interface between the lumen and wall becomes clearer, however, the temporal resolution decreases due to the extra inversion pulses required for blood suppression. Alternatively, separate scans can be acquired for each heart phase, which results in even longer scan times. Although PC MRI is mainly used to measure blood flow velocity, it may also be used to measure the velocity of the vessel wall. Because of the low vessel wall velocity, a relatively low VENC should be used, in the order of $1-5 \mathrm{~cm} / \mathrm{s}$. This, together with the need for an extra reference image, lowers the temporal resolution even more, compared to cine MRI. Instead of measuring velocity, a modified PC MRI protocol called Displacement Encoding using Stimulated Echoes (DENSE) can be used to record tissue displacement (94). Strain encoding (SENC) MRI techniques are able to directly encode tissue strain in the acquired images, but can only be used for through-plane strain data (95), and not in-plane radial strain imaging. Also, high temporal resolution requirements lead to spatial resolutions unfit for carotid artery imaging (96). Future developments in DENSE or PC MRI sequences may provide accurate displacement or velocity data of the arterial wall. For now, the most promising techniques to derive carotid artery plaque deformation are postprocessing techniques based on black blood cine MRI data (figure 3). The effectiveness of these 
techniques highly depends on the spatial and temporal resolutions and on the contrast within the MR images. In general, a voxel size of $0.6 \mathrm{~mm}^{3}$ or lower seems to provide enough voxels for image registration. However, increasing the spatial resolution automatically means a decrease in temporal resolution, because of a longer required read-out time per voxel. Additionally, smaller voxels produce less signal, thereby lowering the SNR. The optimal set of spatiotemporal resolutions and SNR is therefore dependent on the measure (displacement, velocity, or strain), the MRI hardware at hand, and the desired application. Post-processing techniques like non-rigid image registration techniques strongly rely on the quality of the images and are also susceptible for errors due to out-of-plane motion or inadequate registration parameters [Nederveen et al. J Biomech 2014].

MR strain imaging is a potential non-invasive imaging tool to assess carotid artery plaque vulnerability. By identifying high strain spots, that correspond to soft plaque regions, vulnerable plaques may be distinguished from stable plaques and clinical decision making may benefit from this. To identify soft spots (high strain) in carotid artery plaques, the best variable is tissue strain, as assessed using intravascular palpography (91). As strain is a derivative of displacement it is, however, highly susceptible to noise. Evaluating displacement itself may be more promising, as it is less noisy and more homogeneous over the plaque. The disadvantage of displacement measurements is that local tissue inhomogeneities may be impossible to identify. As stresses and strains in circumferential direction of a plaque are the most relevant parameters for plaque rupture, the circumferential displacement seems to be the most appropriate parameter for plaque type evaluation. Besides serving as a potential risk parameter, cyclic displacement of the carotid artery and plaque may also be used as input for fluid-structure interaction (FSI) models. In these models, carotid flow analyses are done while accounting for the cyclic movement of the solid tissue [Yang et al. J. Biomech. 2010; Huang et al. J Biomech 2014]. By measuring the movement, modeling assumptions like wall thickness and stiffness can be avoided, increasing the accuracy of the FSI models.

Identifying stable plaques with significant luminal narrowing using MR strain imaging may lead to reevaluation of the indications for carotid endarterectomy. On the other hand, identifying vulnerable plaques with MR strain imaging which do not cause substantial lumen narrowing may improve clinical decision making. Although in research settings substantial advances have been made and plausible deformation and strain data of carotid arteries have been shown, current clinical MR machines are generally unable to run the required experimental MRI protocols and to provide the spatial and temporal resolutions required to measure carotid plaque deformations.

\section{Conclusions}

Carotid atherosclerotic plaques can be non-invasively characterized by high resolution multi-contrast MRI protocols. Plaque geometry and typical plaque features can be derived by combining multiple MRI sequences. However, new MRI-based techniques have been developed focusing on the functional behavior of tissue. In this review, we presented the current status of MRI-based biomechanical analyses that have the potential to improve carotid artery plaque diagnostics. At this moment, limited spatial and temporal resolutions and low SNR limit the accuracy of these biomechanical analyses. In the future, better MRI systems, faster sequences, and more dedicated MR imaging protocols will become available, specifically for carotid artery plaques. Validation of the discussed techniques are essential and will become within reach with improved MR techniques. 
Although significant advances still need to be made, MR flow imaging, MRI-based biomechanical modeling, and MR strain imaging may, together or separately, lead to improved risk assessment of carotid artery plaques and may provide input for the clinical decision making of carotid endarterectomy or medical treatment.

\section{Acknowledgements}

The authors would like to acknowledge M. Cibis and H.A. Nieuwstadt (Erasmus MC), and A.J. Brown (University of Cambridge) for their contributions to this work. 


\section{References}

1. Underhill HR, Hatsukami TS, Fayad ZA, et al. MRI of carotid atherosclerosis: clinical implications and future directions. Nat Rev Cardiol [Internet] 2010 [cited 2015 Aug 24]; 7: 165-73. Available from: http://www.ncbi.nlm.nih.gov/pubmed/20101259

2. Simpson RJ, Akwei $S$, Hosseini AA, et al. MR imaging-detected carotid plaque hemorrhage is stable for 2 years and a marker for stenosis progression. AJNR Am J Neuroradiol [Internet] 2015 [cited 2015 Aug 24]; 36: 1171-5. Available from: http://www.ncbi.nlm.nih.gov/pubmed/25742988

3. Prabhakaran $\mathrm{S}$, Rundek $\mathrm{T}$, Ramas $\mathrm{R}$, et al. Carotid plaque surface irregularity predicts ischemic stroke: the northern Manhattan study. Stroke [Internet] 2006 [cited 2015 Aug 24]; 37: 2696701. Available from:

http://www.pubmedcentral.nih.gov/articlerender.fcgi?artid=2654324\&tool=pmcentrez\&rend ertype=abstract

4. Singh N, Moody AR, Gladstone DJ, et al. Moderate carotid artery stenosis: MR imagingdepicted intraplaque hemorrhage predicts risk of cerebrovascular ischemic events in asymptomatic men. Radiology [Internet] 2009 [cited 2015 Jul 25]; 252: 502-8. Available from: http://www.ncbi.nlm.nih.gov/pubmed/19508983

5. den Hartog AG, Bovens SM, Koning W, et al. Current status of clinical magnetic resonance imaging for plaque characterisation in patients with carotid artery stenosis. Eur J Vasc Endovasc Surg [Internet] 2013 [cited 2015 Aug 24]; 45: 7-21. Available from: http://www.ncbi.nlm.nih.gov/pubmed/23200607

6. Li F, Yarnykh VL, Hatsukami TS, et al. Scan-rescan reproducibility of carotid atherosclerotic plaque morphology and tissue composition measurements using multicontrast MRI at 3T. J Magn Reson Imaging [Internet] 2010 [cited 2015 Aug 24]; 31: 168-76. Available from: http://www.ncbi.nlm.nih.gov/pubmed/20027584

7. Chen H, Sun J, Kerwin WS, et al. Scan-rescan reproducibility of quantitative assessment of inflammatory carotid atherosclerotic plaque using dynamic contrast-enhanced 3T CMR in a multi-center study. J Cardiovasc Magn Reson [Internet] 2014 [cited 2015 Aug 24]; 16: 51. Available from:

http://www.pubmedcentral.nih.gov/articlerender.fcgi?artid=4237824\&tool=pmcentrez\&rend ertype=abstract

8. Saam T, Ferguson MS, Yarnykh VL, et al. Quantitative evaluation of carotid plaque composition by in vivo MRI. Arterioscler Thromb Vasc Biol [Internet] 2005 [cited 2015 Aug 24]; 25: 234-9. Available from: http://www.ncbi.nlm.nih.gov/pubmed/15528475

9. Bitar R, Moody AR, Leung G, et al. In vivo 3D high-spatial-resolution MR imaging of intraplaque hemorrhage. Radiology [Internet] 2008 [cited 2015 Aug 24]; 249: 259-67. 
Available from: http://www.ncbi.nlm.nih.gov/pubmed/18796681

10. Du J, Corbeil J, Znamirowski R, et al. Direct imaging and quantification of carotid plaque calcification. Magn Reson Med [Internet] 2011 [cited 2015 Aug 24]; 65: 1013-20. Available from: http://www.ncbi.nlm.nih.gov/pubmed/21413065

11. Hatsukami TS, Ross R, Polissar NL, et al. Visualization of fibrous cap thickness and rupture in human atherosclerotic carotid plaque in vivo with high-resolution magnetic resonance imaging. Circulation [Internet] 2000 [cited 2015 Aug 24]; 102: 959-64. Available from: http://www.ncbi.nlm.nih.gov/pubmed/10961958

12. Cai J-M, Hatsukami TS, Ferguson MS, et al. Classification of human carotid atherosclerotic lesions with in vivo multicontrast magnetic resonance imaging. Circulation [Internet] 2002 [cited 2015 Oct 31]; 106: 1368-73. Available from: http://www.ncbi.nlm.nih.gov/pubmed/12221054

13. Cibis M, Potters W V, Gijsen FJH, et al. Wall shear stress calculations based on 3D cine phase contrast MRI and computational fluid dynamics: a comparison study in healthy carotid arteries. NMR Biomed [Internet] 2014 [cited 2015 Aug 13]; 27: 826-34. Available from: http://www.ncbi.nlm.nih.gov/pubmed/24817676

14. Papathanasopoulou $\mathrm{P}$, Zhao S, Köhler $\mathrm{U}$, et al. MRI measurement of time-resolved wall shear stress vectors in a carotid bifurcation model, and comparison with CFD predictions. J Magn Reson Imaging [Internet] 2003 [cited 2015 Aug 19]; 17: 153-62. Available from: http://www.ncbi.nlm.nih.gov/pubmed/12541221

15. Nederveen AJ, Avril S, Speelman L. MRI strain imaging of the carotid artery: Present limitations and future challenges. J Biomech [Internet] 2014 [cited 2014 Jan 27]; 47: 824-33. Available from: http://www.ncbi.nlm.nih.gov/pubmed/24468207

16. Te Boekhorst BC, van Tilborg GA, Strijkers GJ, et al. Molecular MRI of Inflammation in Atherosclerosis. Curr Cardiovasc Imaging Rep [Internet] 2012 [cited 2015 Aug 24]; 5: 60-8. Available from:

http://www.pubmedcentral.nih.gov/articlerender.fcgi?artid=3261392\&tool=pmcentrez\&rend ertype=abstract

17. Malek AM. Hemodynamic Shear Stress and Its Role in Atherosclerosis. JAMA [Internet] American Medical Association; 1999 [cited 2015 May 9]; 282: 2035. Available from: http://jama.jamanetwork.com/article.aspx?articleid=192161

18. Cheng C, Tempel D, van Haperen R, et al. Shear stress-induced changes in atherosclerotic plaque composition are modulated by chemokines. J Clin Invest [Internet] 2007 [cited 2015 Jul 29]; 117: 616-26. Available from:

http://www.pubmedcentral.nih.gov/articlerender.fcgi?artid=1794116\&tool=pmcentrez\&rend ertype=abstract 
19. Matlung HL, Neele AE, Groen HC, et al. Transglutaminase activity regulates atherosclerotic plaque composition at locations exposed to oscillatory shear stress. Atherosclerosis [Internet] 2012 [cited $2015 \mathrm{Jul}$ 29]; 224: 355-62. Available from:

http://www.ncbi.nlm.nih.gov/pubmed/22921425

20. Tang D, Teng Z, Canton G, et al. Sites of rupture in human atherosclerotic carotid plaques are associated with high structural stresses: an in vivo MRI-based 3D fluid-structure interaction study. Stroke [Internet] 2009 [cited 2015 Aug 24]; 40: 3258-63. Available from:

http://www.pubmedcentral.nih.gov/articlerender.fcgi?artid=2753753\&tool=pmcentrez\&rend ertype=abstract

21. Ku DN, Giddens DP, Zarins CK, et al. Pulsatile flow and atherosclerosis in the human carotid bifurcation. Positive correlation between plaque location and low oscillating shear stress. Arteriosclerosis [Internet] 1985 [cited 2015 Jun 3]; 5: 293-302. Available from: http://www.ncbi.nlm.nih.gov/pubmed/3994585

22. LaDisa JF, Bowers M, Harmann L, et al. Time-efficient patient-specific quantification of regional carotid artery fluid dynamics and spatial correlation with plaque burden. Med Phys [Internet] 2010 [cited $2015 \mathrm{Jul}$ 29]; 37: 784-92. Available from:

http://www.pubmedcentral.nih.gov/articlerender.fcgi?artid=2826384\&tool=pmcentrez\&rend ertype=abstract

23. Lee S-W, Antiga L, Steinman DA. Correlations among indicators of disturbed flow at the normal carotid bifurcation. J Biomech Eng [Internet] 2009 [cited 2015 Jul 29]; 131: 061013. Available from: http://www.ncbi.nlm.nih.gov/pubmed/19449967

24. Antiga L, Piccinelli M, Botti L, et al. An image-based modeling framework for patient-specific computational hemodynamics. Med Biol Eng Comput [Internet] 2008 [cited 2015 Jun 19]; 46: 1097-112. Available from: http://www.ncbi.nlm.nih.gov/pubmed/19002516

25. Stalder AF, Russe MF, Frydrychowicz A, et al. Quantitative 2D and 3D phase contrast MRI: optimized analysis of blood flow and vessel wall parameters. Magn Reson Med [Internet] 2008 [cited 2015 Aug 13]; 60: 1218-31. Available from:

http://www.ncbi.nlm.nih.gov/pubmed/18956416

26. Petersson S, Dyverfeldt P, Ebbers T. Assessment of the accuracy of MRI wall shear stress estimation using numerical simulations. J Magn Reson Imaging [Internet] 2012 [cited 2015 Aug 13]; 36: 128-38. Available from: http://www.ncbi.nlm.nih.gov/pubmed/22336966

27. Potters $\mathrm{W}$ V, van Ooij $\mathrm{P}$, Marquering $\mathrm{H}$, et al. Volumetric arterial wall shear stress calculation based on cine phase contrast MRI. J Magn Reson Imaging [Internet] 2015 [cited 2015 Aug 13]; 41: 505-16. Available from: http://www.ncbi.nlm.nih.gov/pubmed/24436246 
28. Oshinski JN, Curtin JL, Loth F. Mean-average wall shear stress measurements in the common carotid artery. J Cardiovasc Magn Reson [Internet] 2006 [cited 2015 Aug 19]; 8: 717-22. Available from: http://www.ncbi.nlm.nih.gov/pubmed/16891231

29. Wu SP, Ringgaard S, Oyre S, et al. Wall shear rates differ between the normal carotid, femoral, and brachial arteries: an in vivo MRI study. J Magn Reson Imaging [Internet] 2004 [cited 2015 Aug 13]; 19: 188-93. Available from: http://www.ncbi.nlm.nih.gov/pubmed/14745752

30. Steinman DA. Image-based computational fluid dynamics modeling in realistic arterial geometries. Ann Biomed Eng [Internet] 2002 [cited 2015 Jul 29]; 30: 483-97. Available from: http://www.ncbi.nlm.nih.gov/pubmed/12086000

31. Oshinski JN, Ku DN, Mukundan S, et al. Determination of wall shear stress in the aorta with the use of MR phase velocity mapping. J Magn Reson Imaging [Internet] 1995 [cited 2015 Aug 13]; 5: 640-7. Available from: http://www.ncbi.nlm.nih.gov/pubmed/8748480

32. Masaryk AM, Frayne $R$, Unal $O$, et al. In vitro and in vivo comparison of three $M R$ measurement methods for calculating vascular shear stress in the internal carotid artery. AJNR Am J Neuroradiol [Internet] 1999 [cited 2015 Aug 19]; 20: 237-45. Available from: http://www.ncbi.nlm.nih.gov/pubmed/10094344

33. Oyre $S$, Ringgaard $S$, Kozerke $S$, et al. Accurate noninvasive quantitation of blood flow, crosssectional lumen vessel area and wall shear stress by three-dimensional paraboloid modeling of magnetic resonance imaging velocity data. J Am Coll Cardiol [Internet] 1998 [cited 2015 Aug 13]; 32: 128-34. Available from: http://www.ncbi.nlm.nih.gov/pubmed/9669260

34. Cheng CP, Parker D, Taylor CA. Quantification of wall shear stress in large blood vessels using Lagrangian interpolation functions with cine phase-contrast magnetic resonance imaging. Ann Biomed Eng [Internet] 2002 [cited 2015 Aug 13]; 30: 1020-32. Available from: http://www.ncbi.nlm.nih.gov/pubmed/12449763

35. Gelfand BD, Epstein FH, Blackman BR. Spatial and spectral heterogeneity of time-varying shear stress profiles in the carotid bifurcation by phase-contrast MRI. J Magn Reson Imaging [Internet] 2006 [cited 2015 Aug 13]; 24: 1386-92. Available from:

http://www.ncbi.nlm.nih.gov/pubmed/17083089

36. Box FMA, van der Geest RJ, van der Grond J, et al. Reproducibility of wall shear stress assessment with the paraboloid method in the internal carotid artery with velocity encoded MRI in healthy young individuals. J Magn Reson Imaging [Internet] 2007 [cited 2015 Aug 13]; 26: 598-605. Available from: http://www.ncbi.nlm.nih.gov/pubmed/17729354

37. Jiang J, Kokeny P, Ying W, et al. Quantifying errors in flow measurement using phase contrast magnetic resonance imaging: comparison of several boundary detection methods. Magn Reson Imaging [Internet] 2015 [cited 2015 Aug 13]; 33: 185-93. Available from: http://www.ncbi.nlm.nih.gov/pubmed/25460329 
38. Herment $\mathrm{A}$, Kachenoura $\mathrm{N}$, Lefort $\mathrm{M}$, et al. Automated segmentation of the aorta from phase contrast MR images: validation against expert tracing in healthy volunteers and in patients with a dilated aorta. J Magn Reson Imaging [Internet] 2010 [cited 2015 Aug 19]; 31: 881-8. Available from: http://www.ncbi.nlm.nih.gov/pubmed/20373432

39. Markl M, Wegent $\mathrm{F}$, Zech $\mathrm{T}$, et al. In vivo wall shear stress distribution in the carotid artery: effect of bifurcation geometry, internal carotid artery stenosis, and recanalization therapy. Circ Cardiovasc Imaging [Internet] 2010 [cited 2015 Aug 19]; 3: 647-55. Available from: http://www.ncbi.nlm.nih.gov/pubmed/20847189

40. van Ooij P, Potters W V, Nederveen AJ, et al. A methodology to detect abnormal relative wall shear stress on the full surface of the thoracic aorta using four-dimensional flow MRI. Magn Reson Med [Internet] 2015 [cited 2015 Aug 20]; 73: 1216-27. Available from: http://www.ncbi.nlm.nih.gov/pubmed/24753241

41. Lorenz R, Bock J, Snyder J, et al. Influence of eddy current, Maxwell and gradient field corrections on 3D flow visualization of 3D CINE PC-MRI data. Magn Reson Med [Internet] 2014 [cited 2015 Aug 13]; 72: 33-40. Available from:

http://www.pubmedcentral.nih.gov/articlerender.fcgi?artid=3872262\&tool=pmcentrez\&rend ertype=abstract

42. O'Brien KR, Cowan BR, Jain M, et al. MRI phase contrast velocity and flow errors in turbulent stenotic jets. J Magn Reson Imaging [Internet] 2008 [cited 2015 Aug 13]; 28: 210-8. Available from: http://www.ncbi.nlm.nih.gov/pubmed/18581344

43. Cheng $C$, Tempel $D$, van Haperen $R$, et al. Atherosclerotic lesion size and vulnerability are determined by patterns of fluid shear stress. Circulation [Internet] 2006/06/07 ed. 2006 [cited 2015 Jul 29]; 113: 2744-53. Available from: http://www.ncbi.nlm.nih.gov/pubmed/16754802

44. van Bochove GS, Straathof R, Krams R, et al. MRI-determined carotid artery flow velocities and wall shear stress in a mouse model of vulnerable and stable atherosclerotic plaque. MAGMA [Internet] 2010 [cited 2014 Jun 10]; 23: 77-84. Available from: http://www.ncbi.nlm.nih.gov/pubmed/20229088

45. Peiffer V, Sherwin SJ, Weinberg PD. Computation in the rabbit aorta of a new metric - the transverse wall shear stress - to quantify the multidirectional character of disturbed blood flow. J Biomech [Internet] 2013 [cited 2015 Aug 13]; 46: 2651-8. Available from: http://www.pubmedcentral.nih.gov/articlerender.fcgi?artid=3807647\&tool=pmcentrez\&rend ertype=abstract

46. He X, Ku DN. Pulsatile flow in the human left coronary artery bifurcation: average conditions. J Biomech Eng [Internet] 1996 [cited 2015 Aug 13]; 118: 74-82. Available from: http://www.ncbi.nlm.nih.gov/pubmed/8833077 
47. Harloff A, Berg S, Barker AJ, et al. Wall shear stress distribution at the carotid bifurcation: influence of eversion carotid endarterectomy. Eur Radiol [Internet] 2013 [cited 2015 Aug 20]; 23: 3361-9. Available from: http://www.ncbi.nlm.nih.gov/pubmed/23812310

48. Gallo D, Steinman DA, Bijari PB, et al. Helical flow in carotid bifurcation as surrogate marker of exposure to disturbed shear. J Biomech [Internet] 2012 [cited 2015 Aug 20]; 45: 2398-404. Available from: http://www.ncbi.nlm.nih.gov/pubmed/22854207

49. Giese D, Wong J, Greil GF, et al. Towards highly accelerated Cartesian time-resolved 3D flow cardiovascular magnetic resonance in the clinical setting. J Cardiovasc Magn Reson [Internet] 2014 [cited 2015 Jul 8]; 16: 42. Available from:

http://www.pubmedcentral.nih.gov/articlerender.fcgi?artid=4230248\&tool=pmcentrez\&rend ertype=abstract

50. Knobloch V, Boesiger P, Kozerke S. Sparsity transform k-t principal component analysis for accelerating cine three-dimensional flow measurements. Magn Reson Med [Internet] 2013 [cited 2015 Aug 13]; 70: 53-63. Available from:

http://www.ncbi.nlm.nih.gov/pubmed/22887065

51. Schnell S, Markl M, Entezari P, et al. k-t GRAPPA accelerated four-dimensional flow MRI in the aorta: effect on scan time, image quality, and quantification of flow and wall shear stress. Magn Reson Med [Internet] 2014 [cited 2015 Aug 13]; 72: 522-33. Available from: http://www.pubmedcentral.nih.gov/articlerender.fcgi?artid=4414256\&tool=pmcentrez\&rend ertype=abstract

52. Barnett HJ, Taylor DW, Eliasziw M, et al. Benefit of carotid endarterectomy in patients with symptomatic moderate or severe stenosis. North American Symptomatic Carotid Endarterectomy Trial Collaborators. N Engl J Med [Internet] 1998/11/13 ed. 1998; 339: 141525. Available from:

http://www.ncbi.nlm.nih.gov/entrez/query.fcgi?cmd=Retrieve\&db=PubMed\&dopt=Citation\&l ist_uids $=9811916$

53. Yuan C, Zhang S, Polissar NL, et al. Identification of fibrous cap rupture with magnetic resonance imaging is highly associated with recent transient ischemic attack or stroke. Circulation [Internet] 2002 [cited 2015 Aug 24]; 105: 181-5. Available from: http://www.ncbi.nlm.nih.gov/pubmed/11790698

54. Chu B, Kampschulte A, Ferguson MS, et al. Hemorrhage in the atherosclerotic carotid plaque: a high-resolution MRI study. Stroke [Internet] 2004/04/03 ed. 2004; 35: 1079-84. Available from:

http://www.ncbi.nlm.nih.gov/entrez/query.fcgi?cmd=Retrieve\&db=PubMed\&dopt=Citation\&l ist_uids $=15060318$

55. Sadat U, Weerakkody RA, Bowden DJ, et al. Utility of high resolution MR imaging to assess carotid plaque morphology: a comparison of acute symptomatic, recently symptomatic and asymptomatic patients with carotid artery disease. Atherosclerosis [Internet] 2009 [cited 2015 
Aug 24]; 207: 434-9. Available from: http://www.ncbi.nlm.nih.gov/pubmed/19520370

56. Altaf N, Daniels L, Morgan PS, et al. Detection of intraplaque hemorrhage by magnetic resonance imaging in symptomatic patients with mild to moderate carotid stenosis predicts recurrent neurological events. J Vasc Surg [Internet] 2008 [cited 2015 Aug 24]; 47: 337-42. Available from: http://www.ncbi.nlm.nih.gov/pubmed/18164171

57. Takaya N, Yuan C, Chu B, et al. Association between carotid plaque characteristics and subsequent ischemic cerebrovascular events: a prospective assessment with MRI--initial results. Stroke [Internet] 2006 [cited 2015 Aug 24]; 37: 818-23. Available from: http://www.ncbi.nlm.nih.gov/pubmed/16469957

58. Richardson PD, Davies MJ, Born G V. Influence of plaque configuration and stress distribution on fissuring of coronary atherosclerotic plaques. Lancet (London, England) [Internet] 1989 [cited 2015 Jul 26]; 2: 941-4. Available from: http://www.ncbi.nlm.nih.gov/pubmed/2571862

59. Sadat $U$, Teng $Z$, Young VE, et al. High-resolution magnetic resonance imaging-based biomechanical stress analysis of carotid atheroma: a comparison of single transient ischaemic attack, recurrent transient ischaemic attacks, non-disabling stroke and asymptomatic patient groups. Eur J Vasc Endovasc Surg 2011; 41: 83-90.

60. Zhu C, Teng Z, Sadat U, et al. Normalized wall index specific and MRI-based stress analysis of atherosclerotic carotid plaques: a study comparing acutely symptomatic and asymptomatic patients. Circ J [Internet] 2010 [cited 2015 Aug 24]; 74: 2360-4. Available from: http://www.ncbi.nlm.nih.gov/pubmed/20834184

61. Sadat U, Teng Z, Young VE, et al. Association between biomechanical structural stresses of atherosclerotic carotid plaques and subsequent ischaemic cerebrovascular events--a longitudinal in vivo magnetic resonance imaging-based finite element study. Eur J Vasc Endovasc Surg [Internet] 2010 [cited 2015 Aug 24]; 40: 485-91. Available from: http://www.ncbi.nlm.nih.gov/pubmed/20724181

62. Li Z-Y, Howarth S, Trivedi RA, et al. Stress analysis of carotid plaque rupture based on in vivo high resolution MRI. J Biomech [Internet] 2006 [cited 2015 Aug 24]; 39: 2611-22. Available from: http://www.ncbi.nlm.nih.gov/pubmed/16256124

63. Holzapfel GA, Mulvihill JJ, Cunnane EM, et al. Computational approaches for analyzing the mechanics of atherosclerotic plaques: a review. J Biomech [Internet] 2014 [cited 2015 Jul 30]; 47: 859-69. Available from: http://www.ncbi.nlm.nih.gov/pubmed/24491496

64. Huang $Y$, Teng $Z$, Sadat $U$, et al. The influence of computational strategy on prediction of mechanical stress in carotid atherosclerotic plaques: comparison of 2D structure-only, 3D structure-only, one-way and fully coupled fluid-structure interaction analyses. J Biomech [Internet] 2014 [cited 2015 Aug 25]; 47: 1465-71. Available from: http://www.pubmedcentral.nih.gov/articlerender.fcgi?artid=3989027\&tool=pmcentrez\&rend 
ertype=abstract

65. Nieuwstadt HA, Akyildiz AC, Speelman L, et al. The influence of axial image resolution on atherosclerotic plaque stress computations. J Biomech [Internet] Elsevier; 2013; 46: 689-95. Available from: http://www.ncbi.nlm.nih.gov/pubmed/23261242

66. Gao H, Long $\mathrm{Q}$, Kumar Das $\mathrm{S}$, et al. Study of carotid arterial plaque stress for symptomatic and asymptomatic patients. J Biomech [Internet] 2011 [cited 2015 Aug 24]; 44: 2551-7. Available from: http://www.ncbi.nlm.nih.gov/pubmed/21824619

67. Nieuwstadt HA, van der Lugt A, Kassar ZAM, et al. Atherosclerotic plaque fibrous cap assessment under an oblique scan plane orientation in carotid MRI. Quant Imaging Med Surg [Internet] 2014 [cited 2015 Feb 12]; 4: 216-24. Available from:

http://www.pubmedcentral.nih.gov/articlerender.fcgi?artid=4137179\&tool=pmcentrez\&rend ertype=abstract

68. Zhu C, Sadat U, Patterson AJ, et al. 3D high-resolution contrast enhanced MRI of carotid atheroma--a technical update. Magn Reson Imaging [Internet] 2014 [cited 2015 Aug 25]; 32: 594-7. Available from: http://www.ncbi.nlm.nih.gov/pubmed/24630443

69. Fan Z, Zhang Z, Chung Y-C, et al. Carotid arterial wall MRI at 3T using 3D variable-flip-angle turbo spin-echo (TSE) with flow-sensitive dephasing (FSD). J Magn Reson Imaging [Internet] 2010 [cited 2015 Jul 20]; 31: 645-54. Available from:

http://www.pubmedcentral.nih.gov/articlerender.fcgi?artid=2841222\&tool=pmcentrez\&rend ertype=abstract

70. Liu W, Balu N, Sun J, et al. Segmentation of carotid plaque using multicontrast 3D gradient echo MRI. J Magn Reson Imaging [Internet] 2012 [cited 2015 Aug 25]; 35: 812-9. Available from:

http://www.pubmedcentral.nih.gov/articlerender.fcgi?artid=3298637\&tool=pmcentrez\&rend ertype=abstract

71. Redgrave JN, Gallagher P, Lovett JK, et al. Critical cap thickness and rupture in symptomatic carotid plaques: the oxford plaque study. Stroke [Internet] 2008 [cited 2015 Aug 25]; 39: 1722-9. Available from: http://www.ncbi.nlm.nih.gov/pubmed/18403733

72. Coolen BF, Poot DHJ, Liem MI, et al. Three-dimensional quantitative T1 and T2 mapping of the carotid artery: Sequence design and in vivo feasibility. Magn Reson Med [Internet] 2015 [cited 2015 Aug 25]; . Available from: http://www.ncbi.nlm.nih.gov/pubmed/25920036

73. de Rotte AAJ, Koning W, Truijman MTB, et al. Seven-tesla magnetic resonance imaging of atherosclerotic plaque in the significantly stenosed carotid artery: a feasibility study. Invest Radiol [Internet] 2014 [cited 2015 Aug 25]; 49: 749-57. Available from:

http://www.ncbi.nlm.nih.gov/pubmed/24918464 
74. Xie $Y$, Yang $Q$, Xie G, et al. Improved black-blood imaging using DANTE-SPACE for simultaneous carotid and intracranial vessel wall evaluation. Magn Reson Med [Internet] 2015 [cited 2015 Aug 25]; . Available from: http://www.ncbi.nlm.nih.gov/pubmed/26152900

75. Fan Z, Yu W, Xie Y, et al. Multi-contrast atherosclerosis characterization (MATCH) of carotid plaque with a single 5-min scan: technical development and clinical feasibility. J Cardiovasc Magn Reson [Internet] 2014 [cited 2015 Feb 17]; 16: 53. Available from:

http://www.pubmedcentral.nih.gov/articlerender.fcgi?artid=4222690\&tool=pmcentrez\&rend ertype=abstract

76. Makhijani MK, Balu N, Yamada K, et al. Accelerated 3D MERGE carotid imaging using compressed sensing with a hidden Markov tree model. J Magn Reson Imaging [Internet] 2012 [cited 2015 Aug 25]; 36: 1194-202. Available from:

http://www.pubmedcentral.nih.gov/articlerender.fcgi?artid=4207358\&tool=pmcentrez\&rend ertype=abstract

77. Ebenstein DM, Coughlin D, Chapman J, et al. Nanomechanical properties of calcification, fibrous tissue, and hematoma from atherosclerotic plaques. J Biomed Mater Res A 2009; 91: 1028-37.

78. Teng $Z$, Zhang $Y$, Huang $Y$, et al. Material properties of components in human carotid atherosclerotic plaques: a uniaxial extension study. Acta Biomater [Internet] 2014 [cited 2015 Jun 24]; 10: 5055-63. Available from:

http://www.pubmedcentral.nih.gov/articlerender.fcgi?artid=4226324\&tool=pmcentrez\&rend ertype=abstract

79. Chai C-K, Speelman L, Oomens CWJ, et al. Compressive mechanical properties of atherosclerotic plaques--indentation test to characterise the local anisotropic behaviour. J Biomech [Internet] 2014 [cited 2015 Aug 27]; 47: 784-92. Available from: http://www.ncbi.nlm.nih.gov/pubmed/24480703

80. Chai C-K, Akyildiz AC, Speelman L, et al. Local anisotropic mechanical properties of human carotid atherosclerotic plaques - characterisation by micro-indentation and inverse finite element analysis. J Mech Behav Biomed Mater [Internet] 2015 [cited 2015 Aug 27]; 43: 59-68. Available from: http://www.ncbi.nlm.nih.gov/pubmed/25553556

81. Akyildiz AC, Speelman L, van Brummelen $\mathrm{H}$, et al. Effects of intima stiffness and plaque morphology on peak cap stress. Biomed Eng Online [Internet] 2011/04/12 ed. BioMed Central; 2011; 10: 25. Available from:

http://www.pubmedcentral.nih.gov/articlerender.fcgi?artid=3090737\&tool=pmcentrez\&rend ertype=abstract

82. Yuan J, Teng Z, Feng J, et al. Influence of material property variability on the mechanical behaviour of carotid atherosclerotic plaques: A 3D fluid-structure interaction analysis. Int j numer method biomed eng [Internet] 2015 [cited 2015 Jul 16]; 31: . Available from: http://www.pubmedcentral.nih.gov/articlerender.fcgi?artid=4528233\&tool=pmcentrez\&rend 
ertype=abstract

83. Franquet A, Avril S, Riche R Le, et al. A new method for the in vivo identification of mechanical properties in arteries from cine MRI images: theoretical framework and validation. IEEE Trans Med Imaging [Internet] 2012 [cited 2013 Nov 5]; 6: 1-16. Available from:

http://ieeexplore.ieee.org/xpls/abs_all.jsp?arnumber=6497629

84. Nieuwstadt HA, Fekkes S, Hansen HHG, et al. Carotid plaque elasticity estimation using ultrasound elastography, MRI, and inverse FEA - A numerical feasibility study. Med Eng Phys [Internet] 2015 [cited $2015 \mathrm{Jul}$ 14]; 37: 801-7. Available from: http://www.ncbi.nlm.nih.gov/pubmed/26130603

85. Liu H, Canton G, Yuan C, et al. Using in vivo Cine and 3D multi-contrast MRI to determine human atherosclerotic carotid artery material properties and circumferential shrinkage rate and their impact on stress/strain predictions. J Biomech Eng [Internet] 2012/04/10 ed. 2012; 134: 11008. Available from:

http://www.ncbi.nlm.nih.gov/entrez/query.fcgi?cmd=Retrieve\&db=PubMed\&dopt=Citation\&l ist_uids $=22482663$

86. Taviani V, Hickson SS, Hardy CJ, et al. Estimation of aortic pulse pressure using fourier velocity encoded M-mode MR. J Magn Reson Imaging [Internet] 2014 [cited 2014 Jan 27]; 39: 85-93. Available from: http://www.ncbi.nlm.nih.gov/pubmed/24339366

87. Lendon $\mathrm{CL}$, Davies MJ, Born G V , et al. Atherosclerotic plaque caps are locally weakened when macrophages density is increased. Atherosclerosis [Internet] 1991/03/01 ed. 1991; 87: 87-90. Available from:

http://www.ncbi.nlm.nih.gov/entrez/query.fcgi?cmd=Retrieve\&db=PubMed\&dopt=Citation\&l ist_uids $=1872926$

88. Walsh MT, Cunnane EM, Mulvihill JJ, et al. Uniaxial tensile testing approaches for characterisation of atherosclerotic plaques. J Biomech [Internet] 2014 [cited 2015 Jul 30]; 47: 793-804. Available from: http://www.ncbi.nlm.nih.gov/pubmed/24508324

89. Chan JMS, Monaco C, Wylezinska-Arridge M, et al. Imaging of the vulnerable carotid plaque: biological targeting of inflammation in atherosclerosis using iron oxide particles and MRI. Eur J Vasc Endovasc Surg [Internet] 2014 [cited 2014 Aug 13]; 47: 462-9. Available from: http://www.ncbi.nlm.nih.gov/pubmed/24594295

90. Millon A, Boussel L, Brevet $\mathrm{M}$, et al. Clinical and histological significance of gadolinium enhancement in carotid atherosclerotic plaque. Stroke [Internet] 2012 [cited 2015 Aug 25]; 43: 3023-8. Available from: http://www.ncbi.nlm.nih.gov/pubmed/22923447

91. Schaar JA, van der Steen AFW, Mastik F, et al. Intravascular palpography for vulnerable plaque assessment. J Am Coll Cardiol [Internet] 2006 [cited 2013 Nov 11]; 47: C86-91. Available from: http://www.ncbi.nlm.nih.gov/pubmed/16631515 
92. Naim C, Cloutier G, Mercure E, et al. Characterisation of carotid plaques with ultrasound elastography: feasibility and correlation with high-resolution magnetic resonance imaging. Eur Radiol [Internet] 2013 [cited 2013 Jun 11]; 23: 2030-41. Available from:

http://www.ncbi.nlm.nih.gov/pubmed/23417249

93. Avril S, Schneider F, Boissier C, et al. In vivo time-resolved sub-pixel measurements of wall deformation in the common carotid artery. 7th Eur Symp Vasc Biomater ESVB 2011 2011; 135 .

94. Lin AP, Bennett E, Wisk LE, et al. Circumferential strain in the wall of the common carotid artery: comparing displacement-encoded and cine MRI in volunteers. Magn Reson Med [Internet] 2008 [cited 2013 Jun 18]; 60: 8-13. Available from:

http://www.pubmedcentral.nih.gov/articlerender.fcgi?artid=2886512\&tool=pmcentrez\&rend ertype=abstract

95. Osman NF. Detecting stiff masses using strain-encoded (SENC) imaging. Magn Reson Med 2003; 49: 605-8.

96. Hamdan A, Thouet T, Kelle $\mathrm{S}$, et al. Strain-encoded MRI to evaluate normal left ventricular function and timing of contraction at 3.0 Tesla. J Magn Reson Imaging 2009; 29: 799-808. 